\title{
Sociobiology
}

RESEARCH ARTICLE - BEES

\section{Variability of Food Stores of Tetragonisca fiebrigi (Schwarz) (Hymenoptera: Apidae: Meliponini) from the Argentine Chaco Based on Pollen Analysis}

\author{
FG VosSLER, GA FAgúNDEZ, DC BLETTLER
}

Laboratorio de Actuopalinología, CICyTTP-CONICET/FCYT-UADER, Diamante, Entre Ríos, Argentina

\author{
Article History \\ Edited by \\ Cândida Maria L. Aguiar, UEFS, Brazil \\ Received 22 September 2014 \\ Initial acceptance 24 October 2014 \\ Final acceptance 13 November 2014

\section{Keywords} \\ honey, "rubiecita", stingless bee, "yatei".

\section{Corresponding author} \\ Favio Gerardo Vossler \\ Laboratorio de Actuopalinología \\ CICYTTP-CONICET/FCYT-UADER \\ Dr. Materi y España, E3105BWA \\ Diamante, Entre Ríos, Argentina \\ E-Mail: favossler@yahoo.com.ar
}

\begin{abstract}
Honey and pollen mass samples of Tetragonisca fiebrigi (Schwarz) from the same and different nests, seasons, and forest types from the Argentine Chaco region were palynologically analyzed and multivariate techniques were applied. The samples from each forest type (Palosantal and Quebrachal) were grouped separately by Cluster Analysis but the phenological records detected that grouping was determined by the season when samples were taken. Honeys and pollen masses were grouped together or fairly closed for all nests due to similar abundance of the different pollen types. Furthermore, honeys were not clustered together with other honeys but with pollen masses. It can be assumed that both nectar and pollen were gathered from the same plant species, supporting the hypothesis that the Dry Chaco melittophilous vegetation is dominated by plants providers of both pollen and nectar, but not exclusively or predominately of one of them. Results of Principal Component Analysis revealed that the foraging behavior of $T$. fiebrigi was governed by random factors such as local differences of flower availability but not by preferences for some plant families. This idea can also be extended to other species of this genus as they concentrated their foraging on different families according to the local vegetation availability in the studied sites.
\end{abstract}

\section{Introduction}

Honey and pollen stores from Tetragonisca species have been reported as a culturally important and appreciated food as well as home medicine since ancient times (Nogueira-Neto, 1997; Arenas, 2003; Cortopassi-Laurino et al., 2006; Zamudio \& Hilgert, 2012; Roig-Alsina et al., 2013). Several studies on diet have been done in Tetragonisca angustula (Latreille) such as Imperatriz-Fonseca et al. (1984), Carvalho et al. (1999), Novais et al. (2013, 2014) in Brazil, Sosa-Nájera et al. (1994) and Martínez-Hernández et al. (1994) in Mexico, Obregón et al. (2013) in Colombia, Flores \& Sánchez (2010) in northwestern Argentina, while only one for the aerial-nesting and aggressive Tetragonisca weyrauchi (Schwarz) (Cortopassi-Laurino \& Nogueira-Neto 2003). No studies have been performed for the ground-nesting Tetragonisca buchwaldi (Friese) neither for Tetragonisca fiebrigi (Schwarz).

It is important to study the botanical origin of food stores of T. fiebrigi in the Chaco region, a large plain of xerophylous forest of about 1,000,000 km² in southern South America (Prado, 1993). In this region, the "rubiecita/rubiecito" or "rubita/rubito" (T. fiebrigi) provides the most reputable honey by local people (Arenas 2003) and it is the most intensively reared stingless bee, together with Scaptotrigona jujuyensis (Schrottky) (Roig-Alsina et al., 2013). Furthermore, it is the most frequent Meliponini species in the forest (Vossler, 2012), being their colonies commonly harvested in the field (Roig-Alsina et al., 2013).

Due to the importance of stingless bees in good practices such as meliponiculture and crop pollination, it is desirable to assess the existence of seasonal and environmental foraging tendencies as well as differences in honey and pollen mass composition from the botanical origin of samples.

The aim of this study was to analyze the variability degree in botanical composition of honey and pollen mass samples from the same and different nests, seasons, and forest types in the Chaco region. 


\section{Materials and methods}

\section{Study area}

One sampling site (El Sauzalito, Argentina) was in Palosantal forest while the other three (Miraflores, Juan José Castelli and Villa Río Bermejito, Argentina) were in Quebrachal forest, which are located no more than $250 \mathrm{~km}$ away from each other. These sites have similar climate conditions, they are strongly seasonal with very hot summer (December to March) and low temperatures and frost during winter (July to September); there is a manifest yearly variation in rainfall, with a marked dry season in winter-spring and a rainy season from October to April (Prado, 1993). The Palosantal forest is characterized by the dominance of "palo santo" trees (Bulnesia sarmientoi, Zygophyllaceae) while the Quebrachal forest by the dominance of "quebracho colorado chaqueño" (Schinopsis balansae, Anacardiaceae), "quebracho colorado santiagueño" (Schinopsis lorentzii, Anacardiaceae) and "quebracho blanco" trees (Aspidosperma quebracho-blanco, Apocynaceae).

\section{Pollen analysis of samples}

Honeys and pollen masses from the same nest were analyzed separately (i.e., they were taken into account as independent samples). A total of 11 nests were analyzed from the four seasons and two forest types (Palosantal and Quebrachal). As only honey was found in nest 14 while in nest 18 only the pollen mass, a total of 10 honey and 10 pollen mass samples were studied (Tables 1 and 2). Honey was sampled from different pots of a nest using a disposable plastic syringe and then homogenized. Therefore, one representative sample of honey was kept per nest. Closed pots were preferred for sampling honey. However, when only open pots were available, honey was kept from them. From 8 to $83.8 \mathrm{~g}$ of honey corresponding to between 6 and 130 honey pots per nest was studied (Table 1). Honey samples were pure in nests 1, 2, 10, 12,14 and 15, while they were contaminated with pollen grains from masses during their sampling in nests 5, 6, 7 and 13 (Table 1).

The pollen masses (the content of pollen cerumen pots) of each nest were mixed and analyzed as an only sample. From 12 to $103 \mathrm{~g}$ of pollen corresponding to between 5 and 55 pollen pots per nest was studied (Table 2). Honey and pollen mass were weighed on an Ohaus CS200 electronic balance with 0.1 gram of readibility. Honey and pollen mass samples were dissolved with a glass rod in $200 \mathrm{ml}$ of distilled water at $80-90{ }^{\circ} \mathrm{C}$ and then with a magnetic stirrer for 10- 15 minutes. Five milliliters of this mixture was centrifuged at $472 \mathrm{~g}$ (Pendlenton, 2006) and the sediment was dehydrated using acetic acid and acetolyzed (Erdtman, 1960), mounted in slides using a glicerine-gelatin mixture and identified using a Nikon Eclipse E200 light microscope at 400 and $1000 \mathrm{x}$ magnification. Pollen identification was carried out by comparing pollen provision slides with the pollen reference of plants grown in the sites sampled. The identification of the type Gleditsia amorphoides was dubious, as it was absent in the sampled area.
For this reason, its family was named as Fabaceae?. The counting of 500 pollen grains per slide was made for honey samples, while a total of 300-500 grains for pollen masses.

The reference pollen collection was made from flower buds of plant species collected in various localities from the Chaco province of Argentina (Juan José Castelli (25 ${ }^{\circ} 56^{\prime}$ S- $60^{\circ} 37^{\prime}$

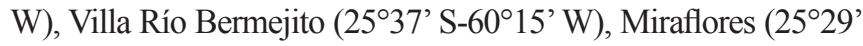
S-6 $\left.1^{\circ} 01^{\prime} \mathrm{W}\right)$ and El Sauzalito $\left(24^{\circ} 24^{\prime}\right.$ S- $\left.61^{\circ} 40^{\prime} \mathrm{W}\right)$ ). These plant specimens were pressed, dried, identified by the author and deposited in the Herbaria of the Museo of La Plata (LP) and the Museo Argentino de Ciencias Naturales "Bernardino Rivadavia" (BA), Buenos Aires, Argentina. Flowering phenology was recorded in these sites during most months except March, May and June (Table 3). Bees were identified by Arturo Roig-Alsina and deposited in the Entomology Collection of the Museo Argentino de Ciencias Naturales “Bernardino Rivadavia", Buenos Aires, Argentina.

\section{Multivariate analysis}

The Cluster Analysis and Principal Component Analysis were the two multivariate techniques applied. The PAST statistic package (Hammer et al., 2008) was used. For Cluster Analysis, the algorithm UPGMA (Unweighted pair-group average) and Bray-Curtis distance were applied to the percentage values of the data matrix in Q-mode. The highest similarity level is 1.00 and indicates $100 \%$ of similarity among pollen composition of samples. The cophenetic correlation coefficient was taken into account as a distortion measurement of the dendrogram (Sokal $\&$ Rohlf, 1962), being values higher than 0.8 indicators of well groupings in the dendrogram compared to the original similarity matrix (Sneath \& Sokal, 1973).

For Principal Component Analysis (PCA), a correlation matrix was applied to the data matrix in Q-mode and R-mode. The Scree plot (simple plot of eigenvalues) was used to cut-off the number of significant principal components. After this curve starts to flatten out, the corresponding components may be regarded as insignificant. The eigenvalues expected under a random model (Broken Stick) were also plotted and the ones under this curve represent non-significant components (Jackson, 1993). The first three principal components (PC I, PC II and PC III) that made up the greatest part of the variability were graphed.

\section{Results}

\section{Cluster Analysis}

The dendrogram of samples of honeys and pollen masses of $T$. fiebrigi showed a high value of cophenetic correlation coefficient (0.879) (Fig 1). Two main groups can be seen within the dendrogram, diverging at 0.1 similarity level (samples of these groups are only $10 \%$ similar). Group A (11 samples) is composed of four subgroups diverging at low similarity values $(0.2-0.3)$ while group B of two subgroups diverging at a medium similarity value (0.4) (Fig 1). 


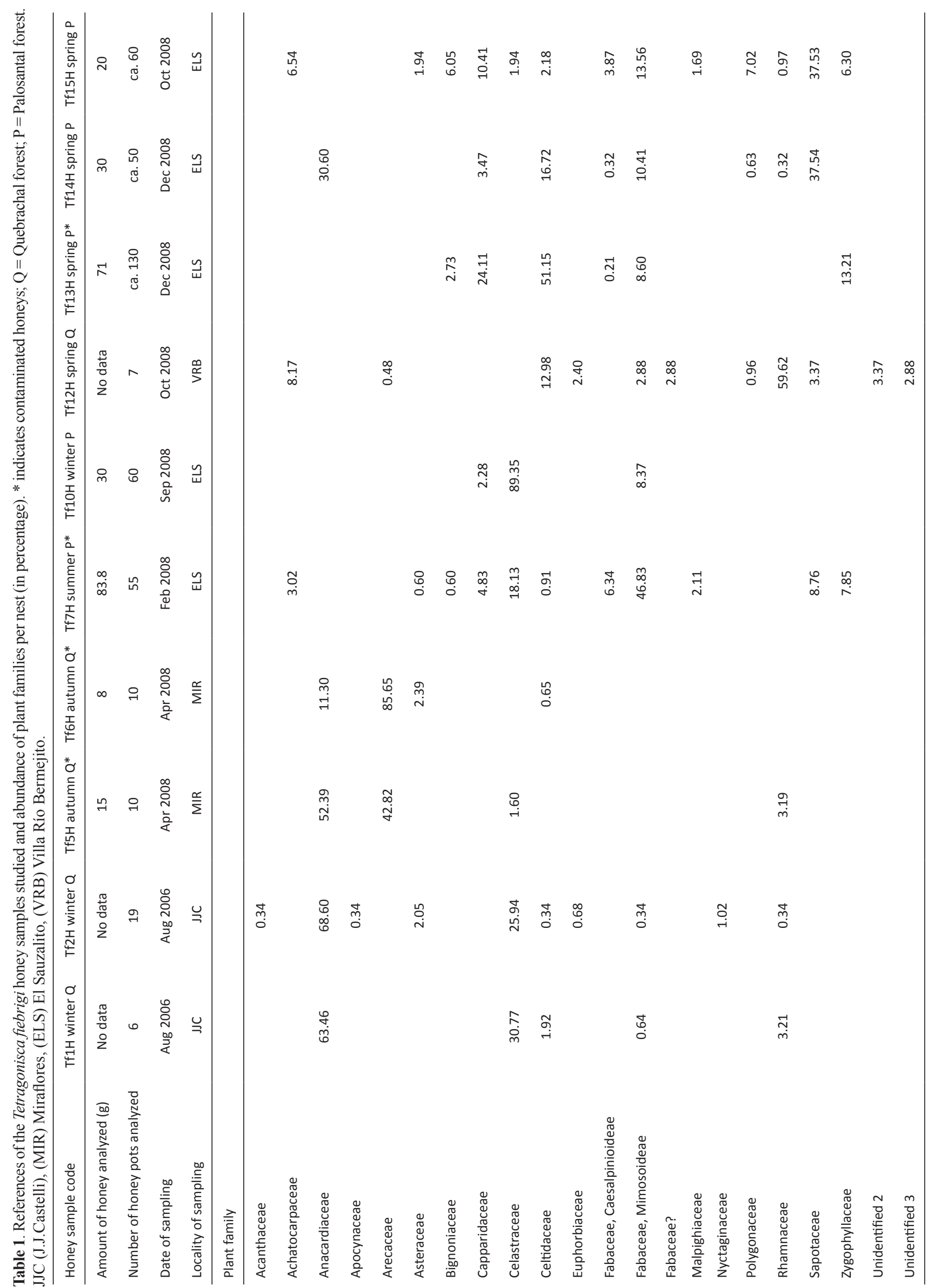




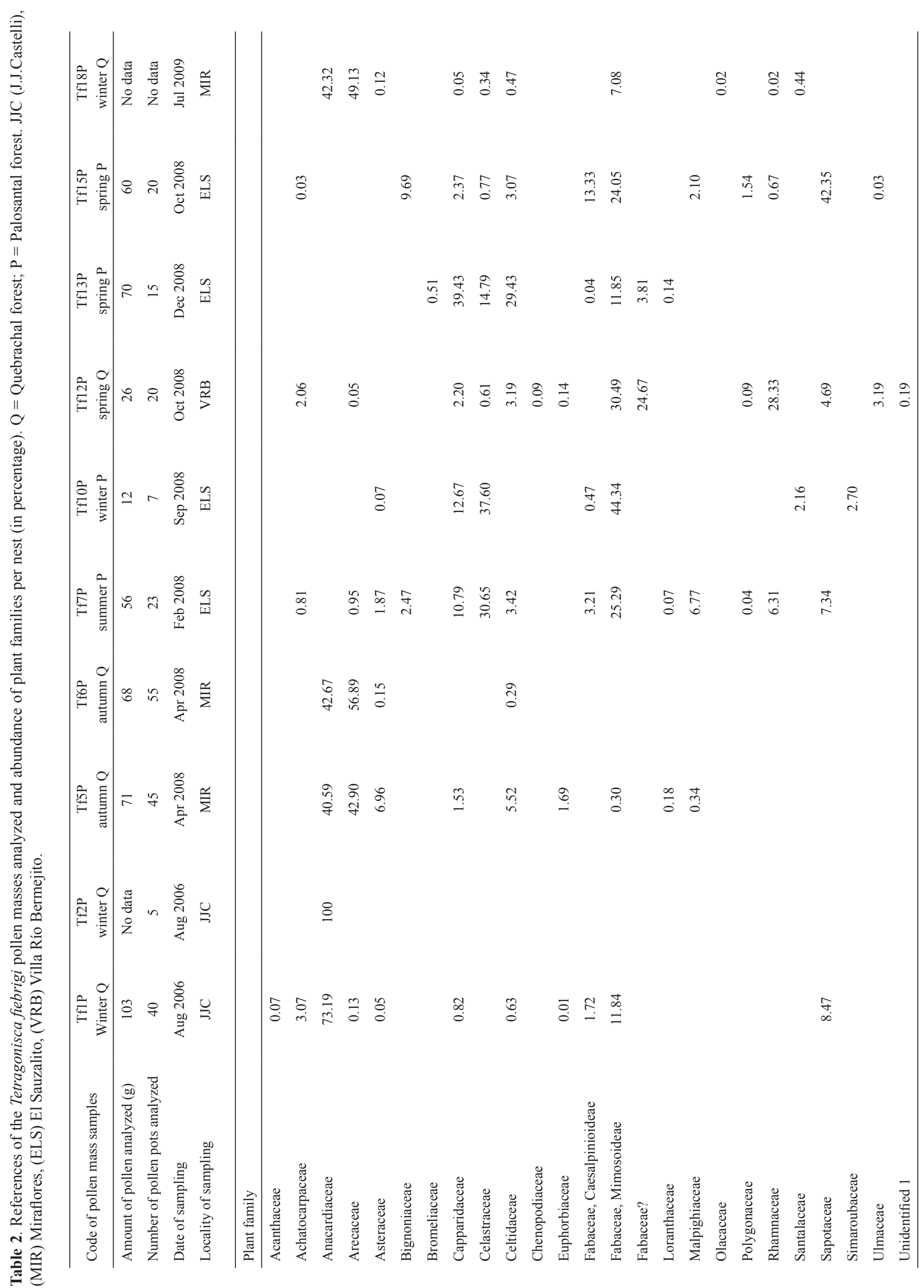




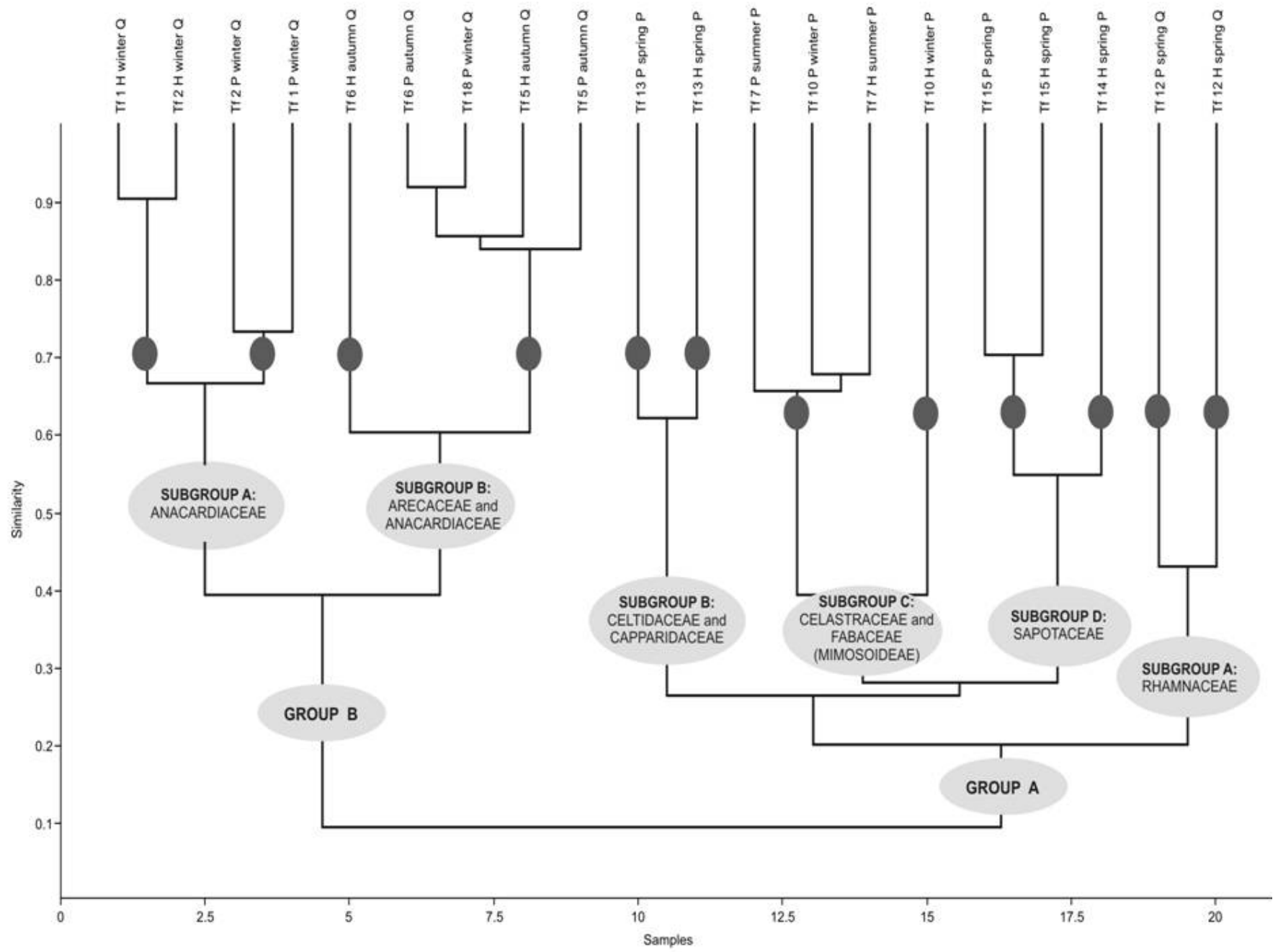

Fig 1. Dendrogram showing the two groups and six subgroups of honey and pollen mass samples of Tetragonisca fiebrigi.

Samples from group A are dominated by various plant families, while those from group B are dominated by one or codominated by two families. In each of the four subgroups of group A, different families are important. Subgroup A has important percentages of Rhamnaceae, B of Celtidaceae and Capparidaceae, $\mathrm{C}$ of Celastraceae and Fabaceae (Mimosoideae), and D of Sapotaceae. Each subgroup has two sets differing according to the dominance and/or codominance of some of their families. Subgroup A has one set (Tf $12 \mathrm{H}$ spring Q) dominated by Rhamnaceae and another codominated by Fabaceae (Mimosoideae), Rhamnaceae and Fabaceae? (Tf 12 P spring Q); subgroup B has one set (Tf $13 \mathrm{H}$ spring P) dominated by Celtidaceae and in a lesser scale composed of Capparidaceae and Zygophyllaceae, while the other set (Tf $13 \mathrm{P}$ spring $\mathrm{P}$ ) is codominated by Capparidaceae and Celtidaceae and in a lesser scale composed of Celastraceae and Fabaceae (Mimosoideae); subgroup $\mathrm{C}$ has one set ( $\mathrm{Tf} 10 \mathrm{H}$ winter $\mathrm{P}$ ) dominated by Celastraceae and another codominated and/or dominated either by Celastraceae or Fabaceae (Mimosoideae); and subgroup $\mathrm{D}$ is composed of two sets, one of them codominated by Sapotaceae, Fabaceae (Mimosoideae), Capparidaceae (in honey) (Tf 15 H spring P) or Sapotaceae, Fabaceae (Mimosoideae),
Fabaceae (Caesalpinioideae) and Bignoniaceae (in pollen mass) (Tf $15 \mathrm{P}$ spring $\mathrm{P}$ ) while the other set is codominated by Sapotaceae, Anacardiaceae, Celtidaceae and Fabaceae (Mimosoideae) (Tf $14 \mathrm{H}$ spring P). The subgroup A of group B is dominated by Anacardiaceae, while the subgroup B is codominated by Arecaceae and Anacardiaceae.

\section{Principal Component Analysis}

Principal Component Analysis and Cluster Analysis partly agreed in the grouping of samples (Figs 1, 2 and 3). In Q-mode, the Principal Component I (Figs 2 and 3) placed sample Tf $2 \mathrm{H}$ winter $\mathrm{Q}$ on the top left corner (dominated by Anacardiaceae and Celastraceae), samples Tf $12 \mathrm{H}$ spring Q and Tf 12 P spring Q (high percentages of Rhamnaceae) on the extreme right and the remaining samples clustered together in the middle (Figs 2 and 3). Families Rhamnaceae, Fabaceae?, Ulmaceae, Unidentified 1 and Chenopodiaceae are the major contributors to the Principal Component I (being 16.35\% of the total variability) (Supplementary material 1).

The Principal Component II (Fig 2) separates samples Tf 2 $\mathrm{H}$ winter Q and Tf $12 \mathrm{H}$ spring Q to the top of the graph and both 
samples of nest 15 (the honey sample codominated by Sapotaceae, Fabaceae (Mimosoideae) and Capparidaceae, and the pollen sample by Sapotaceae, Fabaceae (Mimosoideae), Fabaceae (Caesalpinioideae) and Bignoniaceae) to the bottom of the graph and the remaining samples to the middle. Families Bignoniaceae, Fabaceae (Caesalpinioideae), Sapotaceae, Fabaceae (Mimosoideae) and Euphorbiaceae are the major contributors to the Principal Component II (being 15.02\% of the total variability) (Supplementary material 1).

The Principal Component III (Fig 3) separates the honey sample of nest 12 (dominated by Rhamnaceae) from the pollen sample

\section{Variability of nest samples of Tetragonisca fiebrigi}

The Principal Component I (R-mode) shows that certain families (Anacardiaceae and Arecaceae) are in the extremes of the axes, while Principal Component II shows that Fabaceae (Mimosoideae), Celastraceae and Sapotaceae are the most distant (Fig 4) The association of these families allowed for the differentiation of groups of samples, those from fall and winter (dominated by Anacardiaceae and Arecaceae) (PC I in Supplementary material 1; Group B of Cluster Analysis)

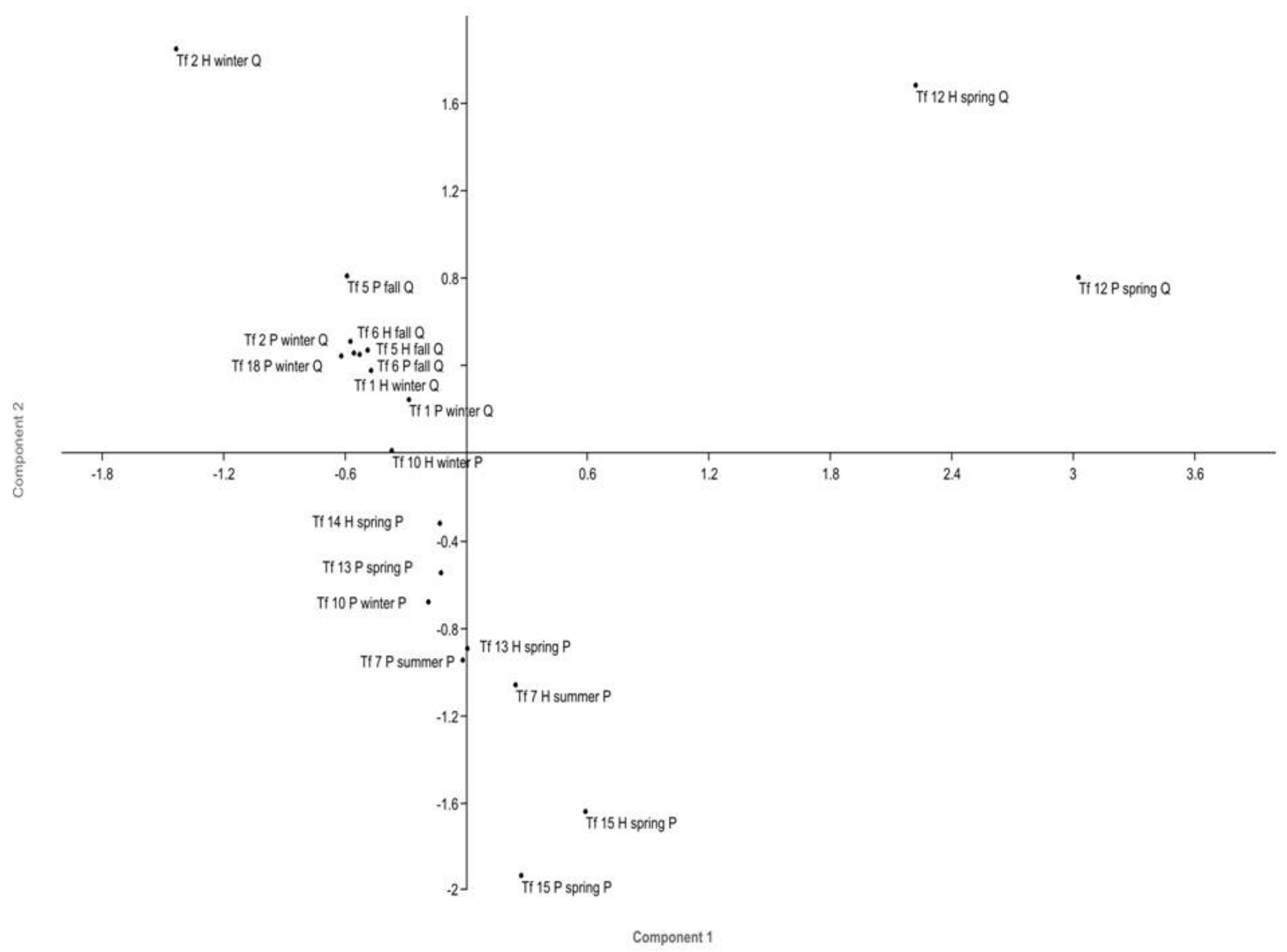

Fig 2. Two-dimensional graph of the Principal Components 1 and 2 showing the distribution of store samples.

of the same nest (codominated by Rhamnaceae, Fabaceae (Mimosoideae) and Fabaceae?) placing them to the bottom and top of the graph, respectively; and the rest in the middle (Fig 3). The three unidentified families (Unidentified 2, 3 and 1), Chenopodiaceae and Ulmaceae are the major contributors to the Principal Component III (being $13.24 \%$ of the total variability) (Supplementary material 1).

The first three PC account for only $44.66 \%$ of the total variability. However, the greatest part of the variability of samples is made up by the first 8 principal components $(83.91 \%)$ (Supplementary material 2) as showed by the scree plot (Supplementary material 3 ). from those from spring, summer and winter (in which Anacardiaceae and Arecaceae were absent) (PC II in Supplementary material 1; Group A of Cluster Analysis).

The families which were the greater contributors to each Principal Component (Supplementary material 1) were those exclusive in the samples (such as Rhamnaceae, Fabaceae?, Ulmaceae, Unidentified 1 and Chenopodiaceae for Principal Component I). Due to the fact that only a low percentage of the variability $(44.66 \%)$ was given by the first three principal components (Supplementary material 2), the samples found in the extremes of the axes of each Principal 
Table 3. Flowering phenology of the plant taxa whose ascribed pollen types were found in the stores of Tetragonisca fiebrigi in the Dry Chaco forest. During March, May and June, flowering was not recorded. Plant life-forms: $\mathrm{T}=$ trees, $\mathrm{S}=$ shrubs (more than $1 \mathrm{~m}$ in height), C = climbers and lianas, $\mathrm{H}=$ herbs, semi-shrubs and shrubs less than $1 \mathrm{~m}$ in height, $\mathrm{E}=$ epiphytes.

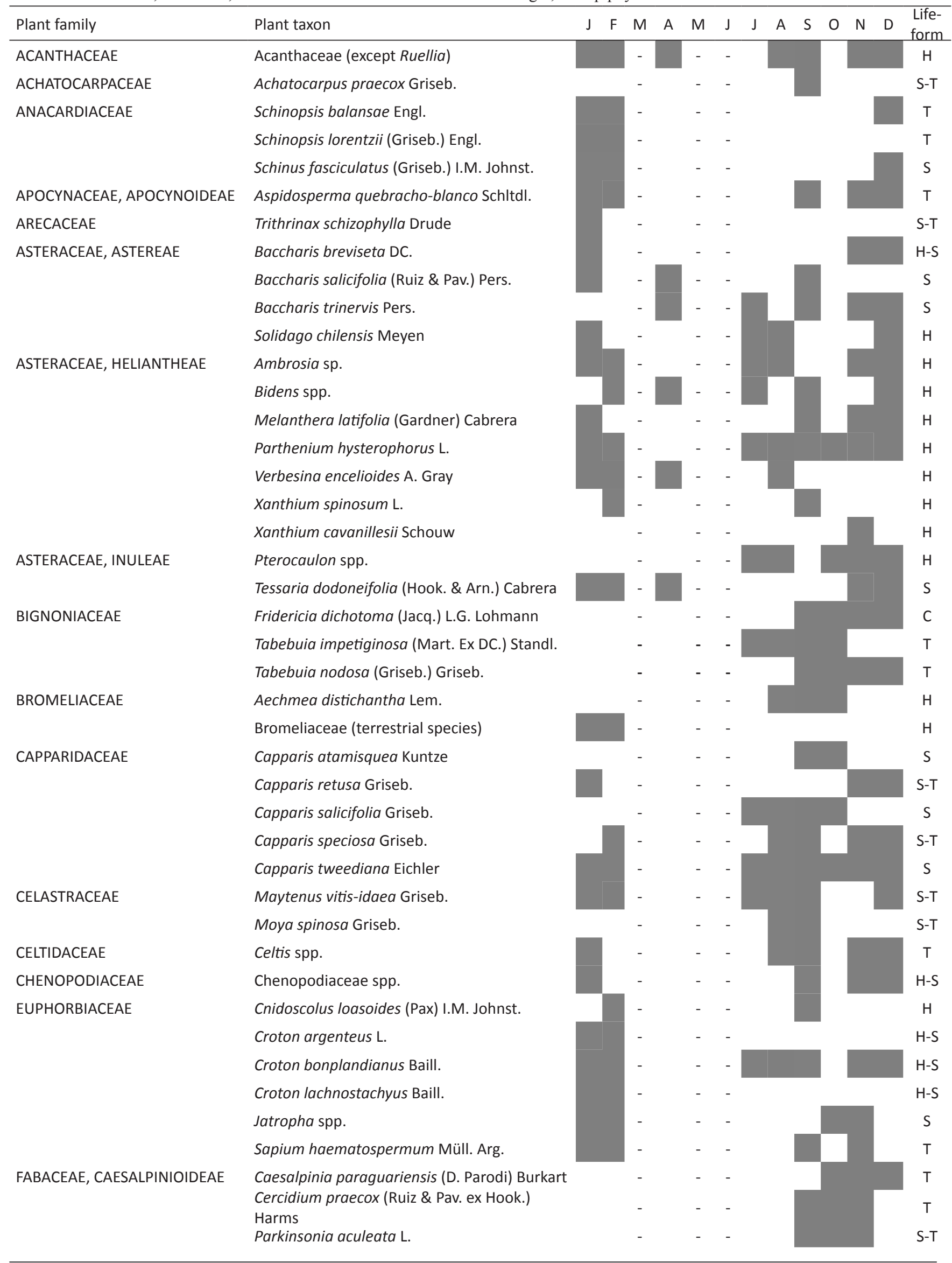


Table 3. Flowering phenology of the plant taxa whose ascribed pollen types were found in the stores of Tetragonisca fiebrigi in the Dry Chaco forest. During March, May and June, flowering was not recorded. Plant life-forms: $\mathrm{T}=$ trees, $\mathrm{S}=$ shrubs (more than $1 \mathrm{~m}$ in height), $\mathrm{C}$ = climbers and lianas, $\mathrm{H}=$ herbs, semi-shrubs and shrubs less than $1 \mathrm{~m}$ in height, $\mathrm{E}=$ epiphytes. (Continuation).

FABACEAE, MIMOSOIDEAE

LORANTHACEAE

MALPIGHIACEAE

NYCTAGINACEAE

OLACACEAE

POLYGONACEAE

RHAMNACEAE

SANTALACEAE

SAPOTACEAE

SIMAROUBACEAE

ULMACEAE

ZYGOPHYLLACEAE
Pterogyne nitens Tul.

Acacia aroma Gillies ex Hook. \& Arn.

Acacia curvifructa Burkart

Albizia inundata (Mart.) Barneby \& J.W.

Grimes

Mimosa detinens Benth.

Prosopis alba Griseb.

Prosopis elata (Burkart) Burkart

Prosopis kuntzei Harms

Prosopis nigra (Griseb.) Hieron.

Prosopis ruscifolia Griseb.

Prosopis vinalillo Stuck.

Prosopis (hybrids)

Struthanthus uraguensis (Hook. \& Arn.) G.

Don

Mascagnia brevifolia Griseb.

Boerhavia diffusa L. var. leiocarpa (Heimerl)

Adams

Ximenia americana L.

Ruprechtia triflora Griseb.

Ziziphus mistol Griseb.

Acanthosyris falcata Griseb.

Sideroxylon obtusifolium (Roem. \& Schult.)

T.D. Penn.

Castela coccinea Griseb.

Phyllostylon rhamnoides (J. Poiss.) Taub. Bulnesia sarmientoi Lorentz ex Griseb.

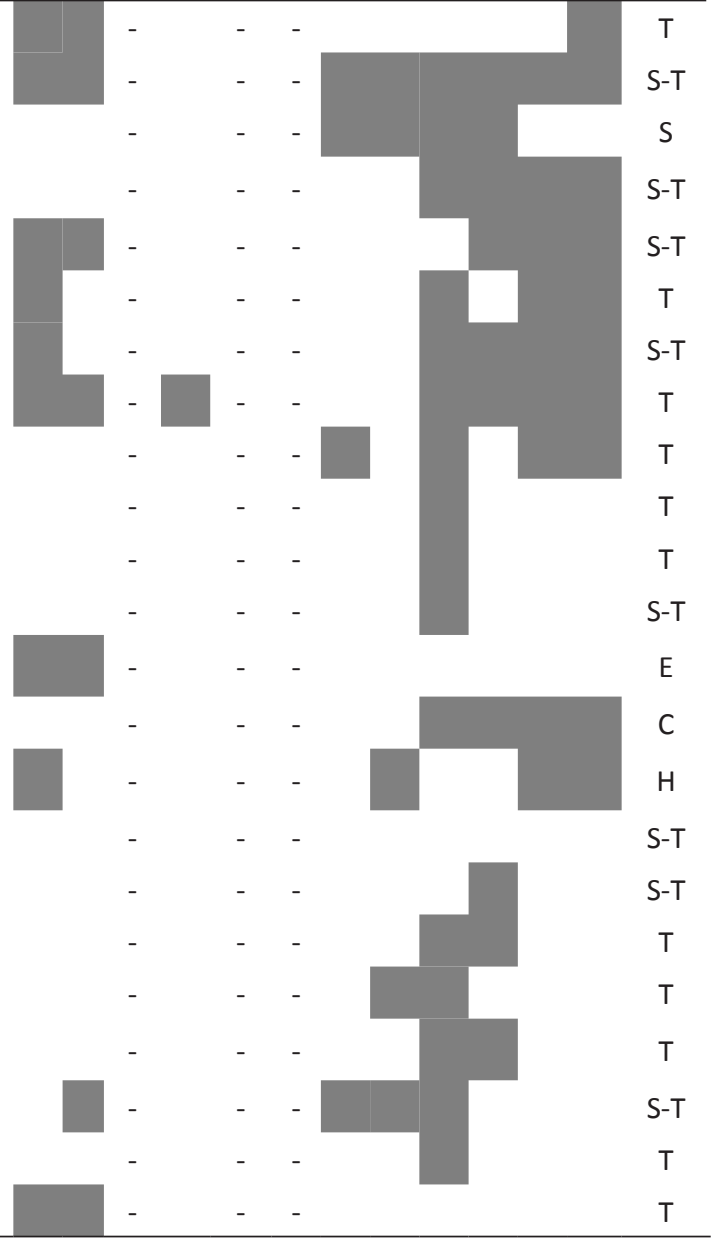

if $12 P$ spring $Q$

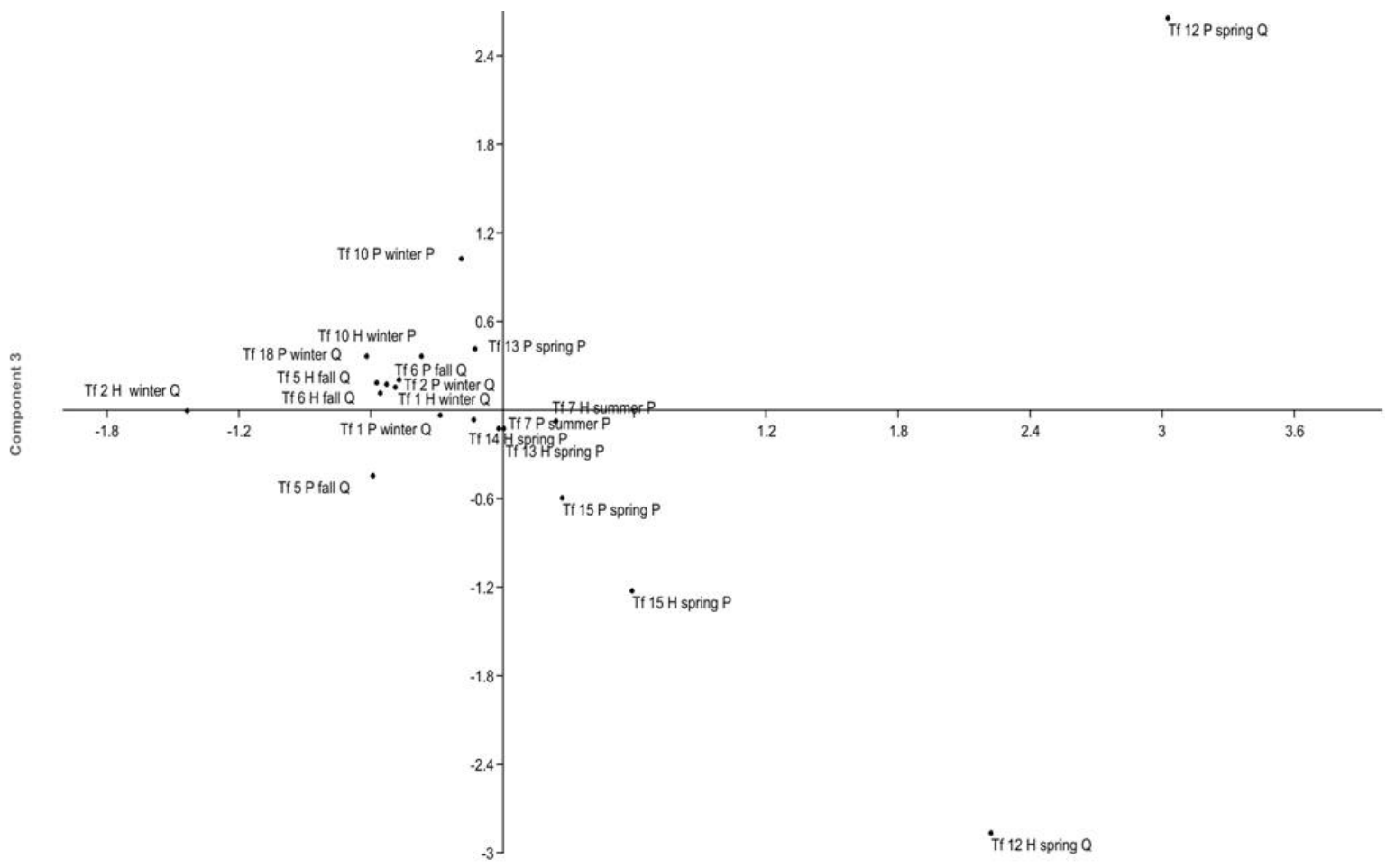

Component 1

Fig 3. Two-dimensional graph of the Principal Components 1 and 3 showing the distribution of store samples. 


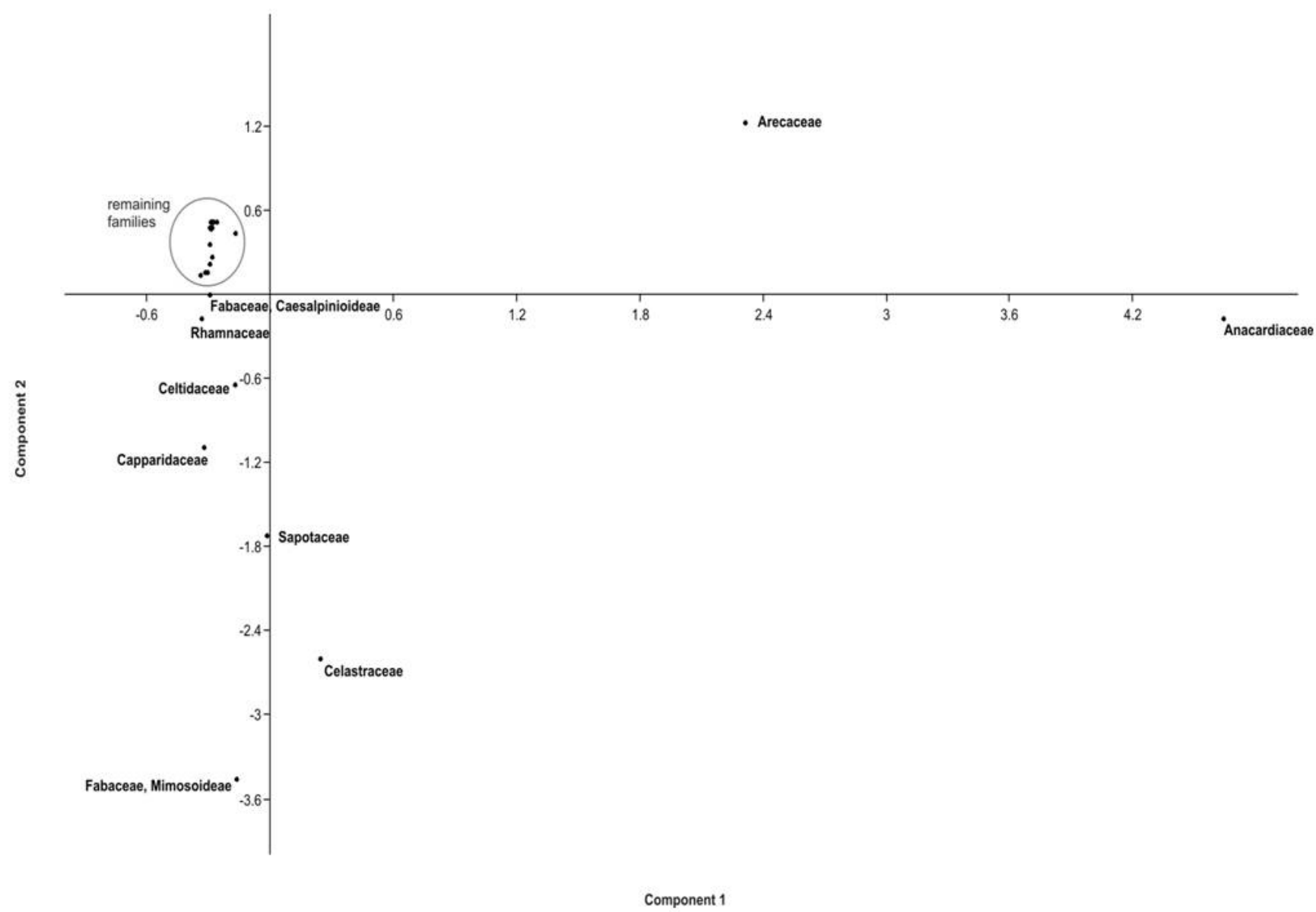

Fig 4. Two-dimensional graph of the Principal Components 1 and 2 showing the distribution of plant families composing the diet of Tetragonisca fiebrigi.

Component were different (but not very different) from the remaining samples although they shared many pollen types.

\section{Discussion}

Were samples clustered by type of forest or season?

The samples from each forest type were clustered separately by Cluster Analysis with the exception of both provisions of nest 12 from Quebrachal that were grouped together with Palosantal samples. This could suggested that botanical composition of these two groups of samples (Groups A and B) is an indicator of the strong differences existent in the floristic composition of these forest types. For instance, the abundance of Schinopsis trees (Anacardiaceae) in the Palosantal is much scarcer than in the Quebrachal (Cabrera, 1971; Prado, 1993). However, samples from group B (all from Quebrachal) were sampled in the fall and winter, while those from group A (all Palosantal plus two Quebrachal samples) mostly in spring suggesting that grouping of samples might not have been achieved by the type of forest. Moreover, the combination of phenological records and pollen analysis of stores detected the cause for these groupings. Fall and winter provisions were composed mainly of floral resources bloomed during summer and fall such as Arecaceae and Anacardiaceae, while spring provisions were composed of spring flowerings alone but not summer-fall floral resources. For instance, the only two winter samples (both stores of nest 10) found in Group A were not clustered in group B together with the remaining samples of winter because they were composed of pollen types from late winter flowerings but not of types foraged during summer-fall. Therefore, it can be said that seasonality strongly influenced the grouping of these store samples. Moreover, Prado (1993) states that no differences in floristic composition exist between Palosantal and Quebrachal plant communities, but only in relative abundance of plant species, supporting the idea that seasonality was the cause of these groupings.

Are there differences in botanical composition among honeys and pollen masses?

Honeys and pollen masses were grouped together or fairly closed for all nests due to similar abundance of the different pollen types. Sampling could be considered as a possible cause of honey contamination as the small cerumen pots of T. fiebrigi are densely packed and fragile. However, both pure (six samples) as well as contaminated honeys (four samples) were closely clustered with pollen masses from the same nests. Although 

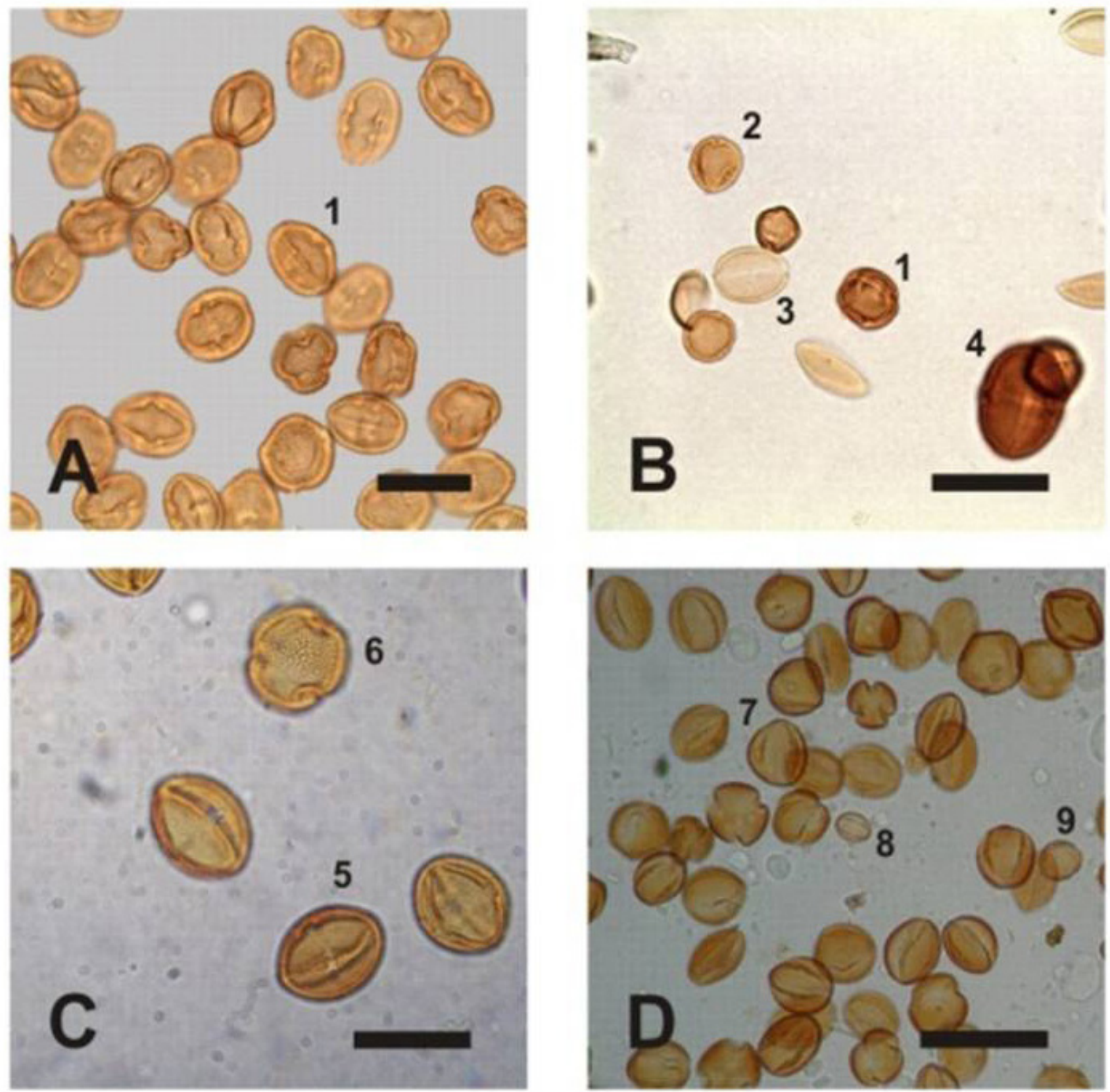

Fig 5. Acetolyzed pollen grains from nest stores, seen in light microscope at $40 \mathrm{x}$ magnification. A-D - Pollen grains of type Schinopsis (Anacardiaceae) (1), Celtis (Celtidaceae) (2), Trithrinax schizophylla (Arecaceae) (3), Sapium haematospermum (Euphorbiaceae) (4), Capparis retusa (Capparidaceae) (5), Castela coccinea (Simaroubaceae) (6), Prosopis (Fabaceae, Mimosoideae) (7), type Maytenus vitis-idaea (Celastraceae) (8), Ziziphus mistol (Rhamnaceae) (9). Bars: $30 \mu \mathrm{m}$ (A and C); $40 \mu \mathrm{m}$ (B); $50 \mu \mathrm{m}$ (D).

contamination can explain the clustering of honey and pollen mass from nests 5, 6, 7 and 13, it does not apply to the remaining six nests (not contaminated honeys). On the other hand, as honeys were not clustered together with other honeys but with pollen masses indicating a similar botanical composition, it can be assumed that both nectar and pollen were gathered from the same plant species. Similar kind of clustering is also observed on the Chaquenian stingless bees Melipona orbignyi Guérin and Geotrigona argentina Camargo \& Moure (Vossler, unpublished data), supporting that the Dry Chaco melittophilous vegetation is dominated by plants providers of both pollen and nectar, but not exclusively or predominately of one of them.
Variability of plant family composition in food stored by Tetragonisca bees

The results of the present study would indicate that the botanical composition of samples of T. fiebrigi is governed by random factors such as local differences of flower availability but not by preferences for particular plant families. For this reason, bees of the genus Tetragonisca have been associated to different plant families according to the vegetation of the study site where samples were taken. For instance, in two sites of Chiapas (Mexico) T. angustula mainly foraged on Fabaceae (Caesalpinioideae), Celtidaceae, Piperaceae, 
Celastraceae, Sapindaceae, Amaranthaceae and Clethraceae (Sosa-Nájera et al., 1994) and on Asteraceae, Euphorbiaceae, Rubiaceae, Rutaceae, Celtidaceae, Sapindaceae, Anacardiaceae and Phytolaccaceae (Martínez-Hernández et al., 1994).

Honeys from coffee agroecosystems from Colombia were dominated by Rubiaceae, Rhamnaceae and Malvaceae (Obregón et al., 2013). In Piracicaba (Brazil), this bee species concentrated its foraging on Liliaceae, Myrtaceae, Fabaceae (Mimosoideae), Fabaceae (Papilionoideae), Celtidaceae and Fabaceae (Caesalpinioideae) (Carvalho \& Marchini, 1999; Carvalho et al., 1999). In honeys from Paraná (Brazil), the most important families were Apiaceae and Fabaceae (Caesalpinioideae) (Cortopassi-Laurino \& Gelli, 1991) while honeys from São Paulo were dominated by Euphorbiaceae, Myrtaceae, Apiaceae and Anacardiaceae (Iwama \& Melhem, 1979).

Pollen stores from São Paulo were mainly composed of Euphorbiaceae, Cecropiaceae and Celtidaceae (Imperatriz-Fonseca et al., 1989). Honeys from different localities of São Paulo state were dominated by either Caricaceae, Asteraceae, Fabaceae (Papilionoideae), Myrtaceae or Fabaceae (Mimosoideae) (Barth et al., 2013). In semi-arid areas from northeastern Brazil covered by Caatinga vegetation, the pollen types more common in honey were from Malpighiaceae, Asteraceae, Myrtaceae, Fabaceae (Mimosoideae), Solanaceae, Anacardiaceae, Arecaceae and Fabaceae (Caesalpinioideae) (Novais et al., 2013). In this same region, pollen stores were dominated by Fabaceae (Mimosoideae), Solanaceae, Moraceae, Fabaceae (Caesalpinioideae) and Malvaceae (Novais et al., 2014). In Yungas forest (northwestern Argentina), honeys of T. angustula were mainly composed of Fabaceae (Mimosoideae), Asteraceae, Myrtaceae and Rutaceae (Flores \& Sánchez, 2010). In the Rio Negro channel (Amazonas, Brazil), pollen stores of $T$. gr. angustula were mainly composed of Cecropiaceae and Moraceae (Rech \& Absy, 2011). In western Amazonas (Acre, Brazil), honey samples of $T$. weyrauchi were dominated by Myrtaceae (Cortopassi-Laurino \& Nogueira-Neto, 2003).

\section{Conclusion}

The use of multivariate methods from palynological data allowed the detection of clustering patterns in the food samples of T. fiebrigi. Grouping of samples was determined by the season when samples were taken but not by type of forest. Honeys and pollen masses were grouped together or fairly closed for all nests due to similar abundance of the different pollen types. Furthermore, honeys were not clustered together with other honeys but with pollen masses. Nectar and pollen were gathered from the same plant species, supporting the hypothesis that the Dry Chaco melittophilous vegetation is dominated by plants providers of both pollen and nectar, but not exclusively or predominately of one of them. The foraging behavior of T. fiebrigi was governed by random factors such as local differences of flower availability but not by preferences for some plant families.

\section{Acknowledgments}

We wish to thank Ricardo "Nene" Vossler, Juan Hiperdinger and César Albornoz for their warm hospitality and help during the field studies. We also thank Nora Brea for providing suggestions and comments on the manuscript. This study was supported by CONICET (Consejo Nacional de Investigaciones Científicas y Técnicas).

\section{References}

Arenas, P. (2003). Etnografía y alimentación entre los toba-ñachilamoleek y wichí lhuku'tas del Chaco Central (Argentina). Buenos Aires: P. Arenas, 562 p.

Barth, O.M., Freitas, A.S., Sousa, G.L., \& Almeida-Muradian, L.B. (2013). Pollen and physicochemical analysis of Apis and Tetragonisca (Apidae) honey. Intercienc., 38: 280-285.

Cabrera, A.L. (1971). Fitogeografía de la República Argentina. Bol. Soc. Arg. Bot., 14: 1-42.

Carvalho, C.A.L. \& Marchini, L.C. (1999). Tipos polínicos coletados por Nannotrigona testaceicornis e Tetragonisca angustula (Hymenoptera, Apidae, Meliponinae). Sci. Agric., 56: 717-722.

Carvalho, C.A.L., Marchini, L.C. \& Ros, P.B. (1999). Fontes de pólen utilizadas por Apis mellifera L. e algumas espécies de Trigonini (Apidae) em Piracicaba (SP). Bragantia, 58: 49-56.

Cortopassi-Laurino, M. \& Gelli, D.S. (1991). Analyse pollinique, propriétés physico-chimiques et action antibactérienne des miels d'abeilles africanisées Apis mellifera et de Méliponinés du Brésil. Apidologie, 22: 61-73.

Cortopassi-Laurino, M. \& Nogueira-Neto, P. (2003). Notas sobre a bionomia de Tetragonisca weyrauchi Schwarz, 1943 (Apidae, Meliponini). Acta Amaz., 33: 643-650.

Cortopassi-Laurino, M., Imperatriz-Fonseca, V.L., Roubik, D.W., Dollin, A., Heard, T., Aguilar, I., Venturieri, G.C., Eardley, C. \& Nogueira-Neto, P. (2006). Global meliponiculture: challenges and opportunities. Apidologie, 37: 275-292.

Erdtman, G. (1960). The acetolysis method, a revised description. Sven. Bot. Tidskr., 54: 561-564.

Flores, F.F. \& Sánchez, A.C. (2010). Primeros resultados de la caracterización botánica de mieles producidas por Tetragonisca angustula (Apidae, Meliponinae) en Los Naranjos, Salta, Argentina. Bol. Soc. Arg. Bot., 45: 81-91. 
Hammer, O., Harper, D.A.T. \& Ryan, P.D. (2008). PAST-Palaeontological Statistics, ver.1.81.

Imperatriz-Fonseca, V.L., Kleinert-Giovannini, A., Cortopassi-Laurino, M. \& Ramalho, M. (1984). Hábitos de coleta de Tetragonisca angustula angustula Latreille (Apidae, Meliponinae). Bol. Zool. Univ. São Paulo, 8: 115-131.

Imperatriz-Fonseca, V.L., Kleinert-Giovannini, A. \& Ramalho, M. (1989). Pollen harvest by eusocial bees in a non-natural community in Brazil. J.Trop. Ecol., 5: 239-242.

Iwama, S. \& Melhem, T.S. (1979). The pollen spectrum of the honey of Tetragonisca angustula angustula Latreille (Apidae, Meliponinae). Apidologie, 10: 275-295.

Jackson, D.A. (1993). Stopping rules in principal components analysis: a comparison of heuristical and statistical approaches. Ecology, 74: 2204-2214.

Martínez-Hernández, E., Cuadriello-Aguilar, J.I., Ramírez-Arriaga, E., Medina-Camacho, M., Sosa-Nájera, M.S. \& Melchor-Sánchez, J.E. (1994). Foraging of Nannotrigona testaceicornis, Trigona (Tetragonisca) angustula, Scaptotrigona mexicana and Plebeia sp. in the Tacaná region, Chiapas, Mexico. Grana, 33: 205-217.

Nogueira-Neto, P. (1997). Vida e criação de abelhas indígenas sem ferrão. Edição Nogueirapis: São Paulo, 445 p.

Novais, J.S., Absy, M.L. \& Santos, F.A.R. (2013). Pollen grains in honeys produced by Tetragonisca angustula (Latreille, 1811) (Hymenoptera: Apidae) in tropical semi-arid areas of north-eastern Brazil. Arthrop. Plant Interact., 7: 619-632.

Novais, J.S., Absy, M.L. \& Santos, F.A.R. (2014). Pollen types collected by Tetragonisca angustula (Hymenoptera: Apidae) in dry vegetation in Northeastern Brazil. Eur. J. Entomol. (Ceské Budejovice, Print), 111: 25-34.

Obregón, D., Rodríguez-C, Chamorro, F.J. \& Nates-Parra, G. (2013). Botanical Origin of Pot-Honey from Tetragonisca angustula Latreille in Colombia. In P. Vit, S.R.M. Pedro \& D.W. Roubik (Eds.). Pot honey: A legacy of stingless bees (pp. 337-346). New York: Springer.
Pendlenton, M. (2006). Descriptions of melissopalynological methods involving centrifugation should include data for calculating Relative Centrifugal Force (RFC) or should express data in units of RFC or gravities (g). Grana, 45: 71-72. doi:10.1080/00173130500520479.

Prado, D.E. (1993). What is the Gran Chaco vegetation in South America? I. A review. Contribution to the study of flora and vegetation of the Chaco. V. Candollea, 48: 145-172.

Rech, A.R. \& Absy, M.L. (2011). Pollen sources used by species of Meliponini (Hymenoptera: Apidae) along the Rio Negro channel in Amazonas, Brazil. Grana, 50: 150-161. doi: $10.1080 / 00173134.2011 .579621$

Roig-Alsina, A., Vossler, F.G. \& Gennari, G.P. (2013). Stingless bees in Argentina. In P. Vit, S.R.M. Pedro \& D.W. Roubik (Eds.). Pot honey: A legacy of stingless bees (pp. 125-134). New York: Springer.

Sneath, P.H.H. \& Sokal, R.R. 1973. Numerical taxonomy: the principles of numerical taxonomy. W.H. Freeman, San Francisco, $573 \mathrm{pp}$.

Sokal, R.R. \& Rohlf F.J. 1962. The comparison of dendrograms by objective methods. Taxon, 11: 33-40.

Sosa-Nájera, M.S., Martínez-Hernández, E., Lozano-García, M.S. \& Cuadriello-Aguilar, J.I. (1994). Nectaropolliniferous sources used by Trigona (Tetragonisca) angustula in Chiapas, southern México. Grana, 33: 225-230.

Vossler, F.G. (2012). Flower visits, nesting and nest defence behaviour of stingless bees (Apidae: Meliponini): suitability of the bee species for Meliponiculture in the Argentinean Chaco region. Apidologie, 43: 139-161. doi: 10.1007/s13592-0110097-6

Zamudio, F. \& Hilgert, N.I. (2012). Descriptive attributes used in the characterization of stingless bees (Apidae: Meliponini) in rural populations of the Atlantic forest (Misiones-Argentina). J. Ethnobiol. Ethnomed., 8: 1-10. doi:10.1186/1746-4269-8-9.

This article has online supplementary material that can be retrieved at: http://periodicos.uefs.br/ojs/index.php/sociobiology/rt/ suppFiles $/ 576 / 0$

DOI: 10.13102/sociobiology.v61i4..s713

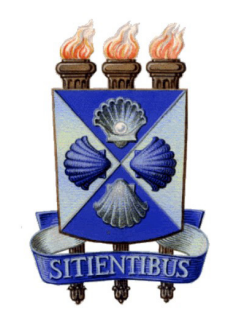

